\title{
The Imitation Ideology in Poetics
}

\author{
Xiaoxia Xu \\ College of Humanities and Social Sciences, China Jiliang University, Hangzhou, Zhejiang, China. \\ 463040868@qq.com
}

Keywords: Poetics; Aristotle; Tragedy; Imitation

\begin{abstract}
Poetics is an art work of Aristotle. In the existing chapters, it mainly discusses the creation of tragedies and epics. At the outset, he mentioned that "poetry is the art of imitating." In this article, it is considered that "imitation" is not only a means but also a purpose in poetry. This article starts from Aristotle's source of mimicking thought, the criticism of Plato and the understanding of poetry imitating, and discusses the imitation thought in "Poetics".
\end{abstract}

\section{The Source of the Imitation Ideology}

Pythagorean School: Imitation of Number. The Pythagorean school believes that "number" is the origin of all things, and all art is the imitation of "number." Like the music theory founded by the Pythagoras school, the tone, rhythm, and rhythm of music actually come from the harmony of the "celestial body." Moreover, the Pythagoras school believes that there is a kind of "soul harmony" in the human body, and this harmony is consistent with the harmony of "number". Only when the music accords with the "number" of the law of operation and is as accurate as the established mathematical model, it can only cause people to enjoy hearing. From this music's accurate imitation of "number," the music and the soul of a person can resonate.

In Aristotle's Poetics, the specification of poetry from media, form, and content can be viewed as an inheritance of the Pythagorean school's view of imitating "number". . He divided the tragedy into six elements: plot, character, language, thoughts, scenes, and arias. The most important of these is the "plot." The ingeniousness of the arrangement of events determines the level of poet's creative level. The plot must have integrity in the entire work. Things have a beginning, a middle, and an end. The length of the plot must be consistent with the viewer's attention. Special provision is the space-time limitation of "tragedy" performances, and it requires a precise control of "numbers". This quantitative arrangement and limitation is precisely the fact that Aristotle examined the necessary role of the law of "number" in tragedy, and poetry is the art of imitating first of all conforming to certain quantitative laws.

Heraclitus: Opposition, Difference and Harmony. Heraclitus believes that "the opposite is the opposite, and the opposite causes harmony." If the bow is pulled to the maximum extent, the greatest power can be accumulated. The harp has a different pitch because of the different degree of tightness of the strings. The mutual coordination of different tones can bring out the most beautiful sound. It is because of the opposite of things that things are led to a rising process. Differences represent the possibility of a combination, which creates many possibilities for artistic imitation. It is precisely for this reason that harmony is not stagnant and motionless, but it should be moving and moving forward.

This view was inherited and used in Aristotle's Poetics. First of all, the objects that poetry imitates are "people in action". This kind of imitation is "imitation of behavior" and represents the allowable variant of poetry imitation. It is not a stagnant art. The plot is the most important part of poetry. It is necessary to describe "people in motion" rather than merely portraying real people. If this kind of movement is invariable, it will cause the work to be boring, because it does not meet the requirements for achieving harmony in opposition and difference. Therefore, the most basic element of the plot, "discovery and reversal," is of utmost importance in the art of poetry. The use of "discovery and reversal" makes the characters turn from reverse to reverse, and the tragic character revealed from them. It will arouse deep pity and fear, and it will meet the purpose of tragedy. 
Democritus: Natural Revelation. Democritus once put forward the idea of music mimicking nature. Mankind imitates nature in many things. We learned weaving from spiders and learned how to build houses with birds. This kind of imitation originates from human instinct, and it is a rational activity based on the actual needs of people after observing things_-people have imitative instincts. His view reveals a certain relationship between art and reality, that is, art is also an imitation of reality.

"Poetics" in the chapter "The Origin and Development of Poetry" talks about "the difference between humans and other animals is that human beings are good at imitating" and "imitation is the nature of human beings". It is undoubtedly the imitation concept of Democritus. The best footnote. What we see here first is Aristotle's respect for reality. Plato does not see natural objects as an imitation of the ideal world. As a real reality, the imitation of reality by art is the true reflection of reality.

Socrates: The possibility of Imitating "Invisible Things". The possibility of imitating "invisible things" is to solve whether the art can maintain the truth of many factors such as ideas, rules, and emotions, and whether it can convey to people a universal emotion that can be observed by observers. Resonance in the heart is not an illusion or an unreal imitation. This problem has been solved in Socrates.

Socrates put "goodness" as the highest category of ideas into ethics, and made people have a universal value, that is, the need to be close to "good", began to form a certain moral norm and value in society. Scale, the "goodness" possessed by human beings already contains a universal psychological emotion and value orientation shared by people, which gives the possibility of mastering "invisible things." Different things can cause the same emotional reactions in different people, precisely because people have obtained the same view of something. Whether it is a tragedy or an epic, an excellent poet grasps the inevitability or possibility of things through "imitation" of individual tragic events. It is based on the universal emotion shared by people and conveys some ideas to people. The realization of this function derives from the possibility of imitating "invisible things."

\section{A Summary of "Imitation of Poetry"}

Poetry is the Art of Imitating. According to Aristotle's definition of the entity, "kind" and "genus" are considered as "second entity" next to "first entity". Poetry is a kind of art form and it is also in "second entity". "In the category.

"Calling them 'poets' is not because they imitate, but because they use a certain metric in their writing." If you simply use language to "imitate," you can distinguish between several prose styles, rhymes, etc. Not only "poetry", from which Aristotle proposed "the difference between various types of art, as the media used in the imitation." The medium used here is the difference in art form. The difference in the use of such media also constitutes the formal causes of various types of art.

Therefore, when we talk about the "imitation" of poetry, we should already include a unique medium that distinguishes "poetry" from other forms of art. This form of poetry is not merely a means of poetry, but rather a poem. The purpose of poetry's "imitation" should be to distinguish poetry from other art forms. In the following text, "Imitated artists, the objects described are the people in action", "Every kind of imitation allows variation, and depending on the object of expression, various imitation methods will also be different." Even if various art forms describe the same thing at the same time, the results reflected in the difference in the way of imitation are different due to the difference in the form of "entity". As the "imitation" of poetry's self-purpose, it should have its own law of occurrence and development. For example, "the goal of comedy is to describe people worse than we are today, and the tragedy is to describe people better than we are ."

Imitation potential. "Poetry imitates what may have happened, and history describes what has happened." From this sentence, we can see that the difference between poetry and history lies in the potential of the development of the things contained in poetry. "The truth of poetry" should not be a fixed, unchanging, immovable, static reality. It should be a dynamic, subjective, or possible reality. 
The things described in poetry should be inevitable or likely to happen. The "necessity" and "possibility" in it are not the same thing that has already happened, and they are intended to reveal a universal fact. This universal fact may not have happened.

Due to the realistic and insightful nature of poetic imitation, it is often more persuasive than real events. In "Poetics," it is said that "dramas can most arouse the viewer's feelings of compassion or fear", which is largely due to the tragic prejudgment of mankind for future events. There are two reasons for mercy. One is that someone has suffered a disaster that should not have been suffered. We have already sensed in advance the potential of things to develop in the direction of tragedy in the tragedies of others; the second is that people who suffer disasters are very similar to ourselves. Pass on the potential of this tragedy to self. Therefore, we should believe that the imitation of poetry contains a propelling force that affects both the fate of the characters and the viewer's heart.

Deceptive Imitation Tragedy. When Kolgia talked about the tragedy, he believed that "a kind of deceitful thing that makes people blundering is not worthy of being deceived, and people who are cheated and cheated will show better artistic appreciation ability." The deceitful understanding of tragedy in his description of this tragedy was inherited in Aristotle. "A thing that cannot happen and that can become credible is more desirable than a thing that may happen and that cannot be made credible." If we evaluate the tragedy based on science or social reality, it is obviously a mistake to criticize it on the basis of a deviation from the purpose of poetry imitation. In this regard, Aristotle used this analogy: "It is not a serious mistake to draw a long-horned doe on the head. If you draw the doe so that you cannot recognize it as a deer, it is a big mistake. Especially wrong."

The tragedy's imitation of reality, even with "deceptive nature" or "never happened in reality" (after all, one cannot be sure that something never happened will not happen in the future), as long as it meets the purpose of poetry itself. That's desirable. This view of the separation of the purpose of poetry itself from the evaluation of ordinary morality is precisely the view of poetry as a self-fulfilling "entity".

Therefore, the "deceptiveness" of this tragedy's imitation should not be regarded as a false existence, as long as the effects caused by it are used "can arouse people's compassion and fear" and achieve the tragedy that Aristotle believes. The purpose should be considered as a reasonable part of "imitation."

\section{Conclusion}

The imitative thoughts involved in Aristotle's poetics have become one of the foundations of Western art's theory and have prospered. This "imitation" should be the universality of the movements contained in the poetic form. Real reproduction. Seeing "imitation" as an active force with great potential is also one of the driving forces for innovation in art itself. What we read in "Poetics" is not only the classic paradigm of tragedies and epic works, but also an innovative possibility of re-exploring reality.

\section{Acknowledgement}

Heilongjiang university education reform project, SJGY20180565.

\section{References}

[1] Luo Xianxian, Aristotle's Poetics: An Interpretation of "Being", Dalian University of Technology,2015.

[2] Zhao Zhenyu, The Path to Catasis: A Metaphysical Study of Aristotle's Poetics, Monthly Theory.2012(10) 40-43.

[3] Liu Xinyu,Liang Xiaochen, On the Ontology of "Imitation Theory" and "Imitating" in Aristotle's Poetics,Literary life.2015 (8) 66.

[4] Tang Yuan, Aristotle's Poetics "Skopos Theory",Xiangtan University,2014. 
[5] Li Zhixiong, On the Classical Narrative Theory in Aristotle's Poetics , Journal of Xiangtan University(Philosophy and Social Science Edition).2006 , 30 (6) 61-65.

[6] Wang Xiumei, Reading Aristotle's Poetics from the Perspective of Tragedy Aesthetics, Literature Education. 2015 (4) :32-32.

[7] Zhang Jingjing, Artistic Imitation Thought in Aristotle's Poetics,Shanghai Normal University,2011.

[8] Qi Xiaohong, Heraclitus's Harmony Beauty Thought and Its Practical Significance, Journal of Chifeng University (Philosophy and Social Science Edition), 2016 , 37 (4) 46-47.

[9] Wang Weihua, Educational Practice: from the Perspective of Aristotle's Practical Philosophy Central China Normal University, Journal of Education, 2007 , 3 (4) 19-23.

[10] Tao Tao, Aristotle on Music and Virtue Education, Civilization and morality, 2013 (1) 58-62. 